\title{
High glucose concentrations per se do not adversely affect human sperm function in vitro
}

\author{
J M D Portela ${ }^{1, *}$, R S Tavares ${ }^{1,3,{ }^{*}}$, P C Mota ${ }^{1,3}$, J Ramalho-Santos ${ }^{1,2}$ and S Amaral ${ }^{1,3}$ \\ ${ }^{1}$ Biology of Reproduction and Stem Cell Group, Center for Neuroscience and Cell Biology (CNC), University of \\ Coimbra, 3004-517 Coimbra, Portugal, 2Department of Life Sciences, University of Coimbra, 3001-401 Coimbra, \\ Portugal and ${ }^{3}$ Institute for Interdisciplinary Research, University of Coimbra, 3004-517 Coimbra, Portugal
}

Correspondence should be addressed to S Amaral; Email: scgamaral@gmail.com

*(J M D Portela and R S Tavares contributed equally to this work and should be considered joint first authors)

\begin{abstract}
Diabetes mellitus (DM) represents one of the greatest concerns to global health and it is associated with diverse clinical complications, including reproductive dysfunction. Given the multifactorial nature of DM, the mechanisms that underlie reproductive dysfunction remain unclear. Considering that hyperglycemia has been described as a major effector of the disease pathophysiology, we used an in vitro approach to address the isolated effect of high glucose conditions on human sperm function, thus avoiding other in vivo confounding players. We performed a complete and integrated analysis by measuring a variety of important indicators of spermatozoa functionality (such as motility, viability, capacitation status, acrosomal integrity, mitochondrial superoxide production and membrane potential) in human sperm samples after incubation with $D$ - and L-glucose $(5,25$, or $50 \mathrm{mM})$ for 24 and $48 \mathrm{~h}$. No direct effects promoted by 25 or $50 \mathrm{mM}$ D-glucose were found for any of the parameters assessed $(P>0.05)$, except for the acrosome reaction, which was potentiated after $48 \mathrm{~h}$ of exposure to $50 \mathrm{mM}$ D-glucose $(P<0.05)$. Interestingly, non-metabolizable L-glucose drastically increased superoxide production $(P<0.05)$ and suppressed sperm motility $(P<0.05)$ and capacitation $(P<0.05)$ after $24 \mathrm{~h}$ of treatment, whereas mitochondrial membrane potential $(P<0.05)$, acrosomal integrity $(P<0.01)$ and viability $(P<0.05)$ were later decreased. The overall results suggest that high glucose levels per se do not influence human sperm function in vitro, which stresses the importance of other factors involved in DM pathology. Nevertheless, the absence of metabolizable glucose contributes to a severe impairment of sperm function and thus compromises male fertility.

Free Portuguese abstract: A Portuguese translation of this abstract is freely available at http://www.reproduction-online.org/content/ 150/1/77/suppl/DC1.

Reproduction (2015) 150 77-84
\end{abstract}

\section{Introduction}

Diabetes mellitus (DM), which is clinically characterized by hyperglycemia, is a degenerative disease with serious and wide-range long-standing consequences in terms of human health (Marx 2002, ADA 2013). Worryingly, DM is progressing at epidemic rates, and the number of cases is predicted to increase about $40 \%$ by 2030 as compared to 2000 (Wild et al. 2004). This rising incidence will unavoidably result in an increased prevalence of DM in men before and during reproductive age (Agbaje et al. 2007). In fact, cumulative evidence suggests that DM may adversely affect male reproductive function on multiple levels (Miller et al. 1981, Lucas et al. 1989, Agbaje et al. 2007, Mulholland et al. 2011, La Vignera et al. 2012). Despite some conflicting results in the literature (La Vignera et al. 2012), standard semen analyses of diabetic individuals in general revealed not only a decrease in sperm motility (Barták et al. 1975, Amaral et al. 2006, Delfino et al. 2007) and concentration (Handelsman et al. 1985, Amaral et al. 2006) but also the presence of a higher number of morphologically abnormal forms with defects in the acrosome, nucleus, mitochondria and plasma membrane (Barták et al. 1975, Vignon et al. 1991, Delfino et al. 2007) as well as generally increased semen plasma abnormalities (Agbaje et al. 2007, Tremellen 2008, Alves \& Oliveira 2013). Interestingly, diabetic men who presented normal semen parameters showed significantly higher levels of damage in sperm nuclear and mitochondrial DNA, probably resulting from supraphysiological glucose levels and related oxidative stress (Agbaje et al. 2007). Additionally, advanced glycation end products that result from oxidative damage have been implicated in an increasing number of diabetic complications and have been detected at higher levels 
in the reproductive tract, seminal plasma and sperm of type 1 and type 2 diabetic males (Wautier \& Schmidt 2004, Mallidis et al. 2007, 2009), which suggests their involvement in reactive oxygen species (ROS)-initiated sperm DNA damage.

Although the existing literature suggests that diabetic conditions might compromise sperm quality and function, the mechanisms by which diabetes influences male fertility remain undefined. Considering that mitochondrial dysfunction has been associated with diabetes (Tremellen 2008, Sivitz \& Yorek 2010) and taking into account the hub role of these organelles in reproduction (Ramalho-Santos et al. 2009), which has been shown by the association of several mitochondrial parameters with sperm quality and function (Ruiz-Pesini et al. 1998, Marchetti et al. 2002, 2012, Gallon et al. 2006, Nakada et al. 2006, Publicover et al. 2008, Sousa et al. 2011, Amaral et al. 2013a), it is possible that mitochondrial functionality might play a role in diabetes-induced alterations at the sperm level.

Therefore, using a previously established in vitro approach (Tavares et al. 2013, 2015, Sousa et al. 2014), we intended to address whether some aspects of sperm function are affected by exposure to high glucose levels, which is the foremost recognized signature of this pathology and one of the major factors responsible for diabetes-associated complications.

\section{Materials and methods}

\section{Chemicals}

Unless stated otherwise, all chemicals and reagents were provided by Sigma-Aldrich.

\section{Human biological material}

Human semen samples were obtained at the Human Reproduction Service of the University Hospitals of Coimbra (Coimbra, Portugal) from 48 healthy, non-diabetic men who were undergoing routine semen analysis for fertility treatment in which male factor was excluded.

All the donors signed informed consents and the biological material was used in accordance with the proper ethical and Internal Review Board (IRB) guidelines provided by the University Hospitals of Coimbra. The present study was approved by the IRB.

Semen samples were obtained by masturbation after 3-5 days of sexual abstinence. Seminal analysis was performed according to the World Health Organization (WHO) guidelines (WHO 2010) and only normozoospermic samples with no detectable leukocytes or other round cells were used.

\section{Experimental design}

After liquefaction, sperm cells were isolated by densitygradient centrifugation (SupraSperm; Medicult-Origio, Jyllinge,
Denmark) and allowed to capacitate in sperm preparation medium (SPM; Medicult-Origio) for at least $3 \mathrm{~h}$ at $37{ }^{\circ} \mathrm{C}$ and $5 \% \mathrm{CO}_{2}$ before initial experiments were performed, except for the capacitation status assay in which spermatozoa were allowed to capacitate under the different glucose conditions for the entire incubation period. Sperm samples, with an adjusted concentration of $10 \times 10^{6}$ spermatozoa $/ \mathrm{ml}$, were then incubated at $37^{\circ} \mathrm{C}$ and $5 \% \mathrm{CO}_{2}$ in PBS supplemented with $0.9 \mathrm{mM}$ $\mathrm{CaCl}_{2}, 0.5 \mathrm{mM} \mathrm{MgCl}, 0.3 \%$ (w/v) BSA, $1 \mathrm{mM}$ sodium pyruvate, $10 \mathrm{mM}$ sodium lactate, and $1 \%(\mathrm{v} / \mathrm{v})$ penicillin/streptomycin, $\mathrm{pH}=7.4$ (Tavares et al. 2013, 2015, Sousa et al. 2014), as well as D-glucose at either: i) $5 \mathrm{mM}$, the optimal concentration for sperm preparation in vitro (Mahadevan et al. 1997, Amaral et al. 2011); ii) $25 \mathrm{mM}$ to mimic the diabetic condition; or iii) $50 \mathrm{mM}$ to evaluate cell response to massive doses of glucose. To control for the possible effects of the increased solution osmolarity being driven by the elevated concentrations of D-glucose, equal concentrations of L-glucose, a non-metabolizable and non-physiologic form of glucose, was used as a control. Media were daily renewed and incubations were maintained over a maximal period of 2 days.

The influence of glucose on sperm was assessed daily by measuring a variety of important indicators of spermatozoa functionality.

\section{Motility and viability evaluation}

Sperm motility and viability, which were assessed using $0.5 \%$ $(\mathrm{w} / \mathrm{v})$ Eosin Y, were determined according to WHO (2010) recommendations and monitored by phase-contrast optical microscopy (Nikon Eclipse E200, Nikon Instruments, Inc., Melville, NY, USA) at $200 \times$ and $400 \times$ magnification respectively. For each condition a total of 200 spermatozoa were evaluated in different fields.

Sperm motility is expressed as the percentage of total motility (i.e., progressive motility + in situ motility) and viability was expressed as the percentage of live spermatozoa.

\section{Capacitation status: assessment of tyrosine phosphorylation}

To further address whether D-glucose has an effect on the sperm capacitation process, spermatozoa were allowed to capacitate under glucose exposure in the PBS-based medium described in the experimental design section, supplemented with $25 \mathrm{mM}$ $\mathrm{NaHCO}_{3}$. Capacitation status was assessed through the detection of phosphorylated tyrosines using a rabbit antiphosphotyrosine polyclonal antibody (1:10; Zymed, San Francisco, CA, USA) as described previously (Ramalho-Santos et al. 2007). Samples were mounted on glass slides with Vectashield Mounting Media containing 4',6-diamidino-2phenylindole (DAPI; Vector Labs, Burlingame, CA, USA) to counterstain spermatozoa nuclei. At least 200 spermatozoa were observed in different fields by means of a Leica fluorescence microscope (Leica DM4000B, Wetzlar, Germany) at $1000 \times$ magnification. Whereas capacitated spermatozoa exhibited green fluorescence in both the flagellum and midpiece, non-capacitated spermatozoa only displayed the 
blue nuclear DAPI counterstain. Results are presented as the percentage of capacitated sperm.

\section{Acrosomal integrity evaluation}

Acrosomal integrity was evaluated using the acrosomal content marker Pisum sativum agglutinin conjugated with FITC (PSAFITC) as described previously (Mota et al. 2012). Briefly, blocked sperm samples were incubated with PSA-FITC (1:200) for $1 \mathrm{~h}$ at $37^{\circ} \mathrm{C}$ and mounted with Vectashield Mounting Media containing DAPI after being washed. At least 200 spermatozoa were examined in different fields by means of a Leica fluorescence microscope (Leica DM4000B) at 1000× magnification. Whereas intact acrosomes exhibited bright green homogeneous fluorescent staining, acrosome-reacted spermatozoa showed either no fluorescence signal in the acrosomal region, heterogeneous spots of fluorescence, or only a fluorescing band at the equatorial segment of the sperm head (Ramalho-Santos et al. 2007). Results are presented as the percentage of spermatozoa with intact acrosome.

\section{Flow cytometric analysis: mitochondrial membrane potential and superoxide production}

Flow cytometric analysis was performed on human spermatozoa following incubation with specific fluorescent probes, as described in the following sections. Sample analysis was performed on a FACSCalibur flow cytometer (BD Biosciences, San Jose, CA, USA) equipped with an argon laser that operated with an excitation wavelength of $488 \mathrm{~nm}$ and coupled with the following emission filters: 530/30 band pass (FL-1/green), $585 / 42$ band pass (FL-2/red), and > $620 \mathrm{~nm}$ long pass (FL-3/ far red).

Based on the distinct light scatter characteristics of the spermatozoa (forward and side scatter), non-sperm specific events were gated out of the analysis (Amaral et al. 2013a). A total of 20000 sperm-specific events per condition were recorded, and data acquisition and analysis were performed using the BD Cell Quest Pro Acquisition program (BD Biosciences).

\section{Evaluation of sperm mitochondrial superoxide production}

Sperm mitochondrial superoxide generation was determined using the fluorescence probe MitoSOX-Red (Molecular Probes, Eugene, OR, USA) as reported previously (Amaral et al. 2013a). Briefly, sperm suspensions $\left(2.5 \times 10^{6}\right.$ spermatozoa $\left./ \mathrm{ml}\right)$ were incubated with $3 \mu \mathrm{M}$ of MitoSOX-Red for $15 \mathrm{~min}$ at $37^{\circ} \mathrm{C}$ in the dark. For each sample an appropriate control was performed by simultaneous incubation with $80 \mu \mathrm{M}$ of antimycin $\mathrm{A}-\mathrm{a}$ mitochondrial complex III inhibitor that is known to produce a burst of mitochondrial superoxide (Amaral et al. 2013a). Results are expressed as the percentage of MitoSOX-positive cells.

\section{Evaluation of sperm mitochondrial membrane potential}

Sperm mitochondrial membrane potential (MMP) was assessed using the fluorescent probe JC-1 (Molecular Probes) which differentially labels mitochondria according to their membrane potential by reversibly shifting the fluorescent emission from green (low MMP) to red (high MMP) (Amaral \& RamalhoSantos 2010, Amaral et al. 2013a, Sousa et al. 2014).

Sperm suspensions $\left(2.5 \times 10^{6} \mathrm{spermatozoa} / \mathrm{ml}\right)$ were stained with $2 \mu \mathrm{M}$ of JC- 1 for $20 \mathrm{~min}$ at $37^{\circ} \mathrm{C}$ in the dark. Additionally, for each sample an appropriate control was prepared by simultaneous incubation with $50 \mu \mathrm{M}$ of p-trifluoromethoxy carbonyl cyanide phenyl hydrazine (FCCP), an uncoupler that collapses MMP (Amaral et al. 2013a, Sousa et al. 2014).

Results are presented as the percentage of sperm-specific events with high MMP following exposure to different concentrations of glucose.

\section{Statistical analysis}

Statistical analysis was performed using the SPSS Software for Windows version 20.0 (SPSS, Inc.). All the variables were evaluated for normal distribution by Shapiro-Wilk test and the homogeneity of variances was assessed by Levene's test.

Statistical comparisons between the control and the different glucose concentrations were performed using a $t$-test or a related Mann-Whitney $U$ test, and Wilcoxon tests were used for non-normal variables. Values of $P \leq 0.05$ were considered significant. Results are presented as means \pm S.E.M. and the number of experiments is indicated.

\section{Results}

\section{Motility and viability}

No significant differences, either in motility or in viability, were detected between samples incubated with glucose at $5 \mathrm{mM}$ and higher concentrations (25 or $50 \mathrm{mM})$ on any day of incubation $(P>0.05$, Fig. 1A and B). Nevertheless, statistically significant differences were found when comparing D-glucose and L-glucose. In fact at day 1, L-glucose-incubated spermatozoa showed a significantly lower motility $(P<0.05$, Fig. 1A), although the viability was not affected $(P>0.05$, Fig. 1B). The percentage of viable cells decreased only after 2 days of incubation with the non-metabolizable substrate $(P<0.05$, Fig. 1B).

\section{Capacitation and acrosomal status}

Capacitation and the subsequent acrosome reaction are essential processes, as only capacitated sperm with an intact acrosome have the ability to fertilize (Ecroyd et al. 2003, Ramalho-Santos et al. 2007). Therefore these processes are considered important indicators of sperm functionality.

As detected by protein tyrosine phosphorylation (Fig. 2A), capacitation was not influenced by the high D-glucose conditions ( $P>0.05$, Fig. 2B). Nonetheless, glucose availability also seemed to be important for sperm capacitation. This started to be particularly evident on day 1 , when the percentage of capacitated spermatozoa incubated in $50 \mathrm{mM}$ L-glucose-containing media was significantly lower than that obtained when 

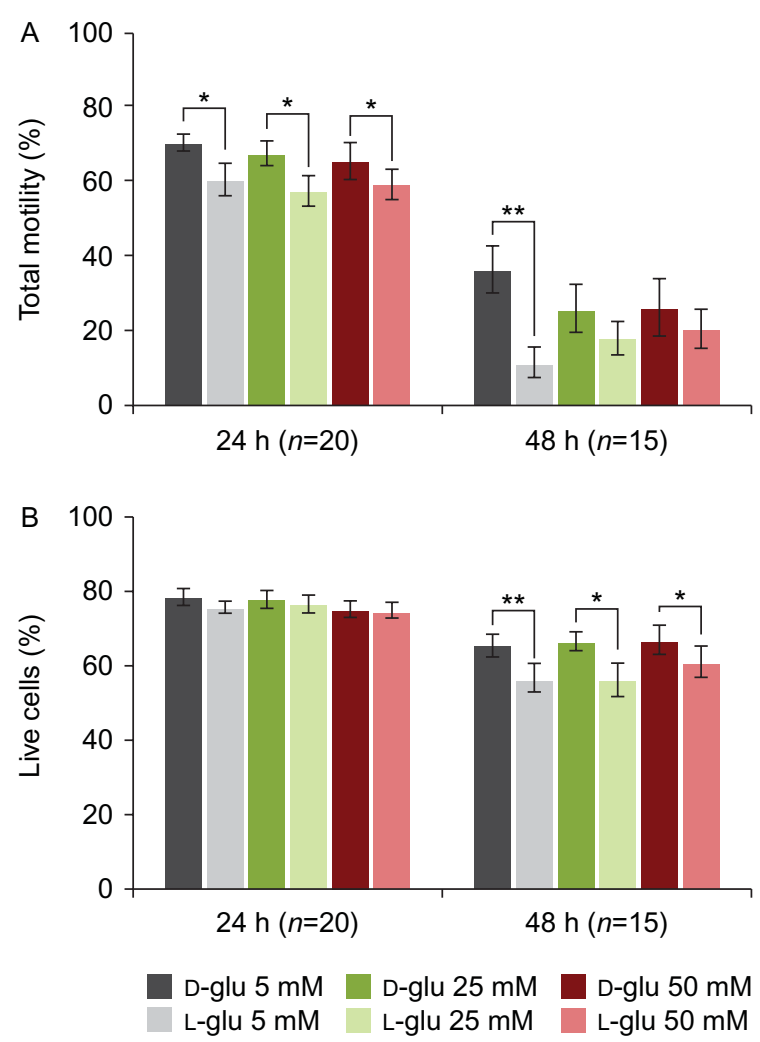

Figure 1 Spermatozoa motility and viability after exposure to different glucose levels. (A) Percentage of total motility. (B) Percentage of live spermatozoa. Samples were incubated for 2 days in PBS-based medium with D-glucose (D-glu), whereas osmotic controls were incubated with L-glucose (L-glu), as described in the Materials and methods section. Results are presented as means \pm S.E.M. and the number of experiments is specified. ${ }^{*} P<0.05,{ }^{* *} P<0.01$.

exposed to $50 \mathrm{mM}$ D-glucose media $(12 \pm 3.77$ and $43 \pm$ $10.62 \%$ respectively, $P<0.05$, Fig. $2 \mathrm{~B}$ ) and became more pronounced on day 2 , when the differences between D- and L-glucose were significant for all of the concentrations ( $P<0.001$, Fig. 2B).

The percentage of intact acrosomes (Fig. 3A) was not statistically different between the spermatozoa incubated with $5 \mathrm{mM}$ D-glucose and those incubated with high glucose levels on day 1 ( $P>0.05$, Fig. 3B). However, after 2 days of incubation, the higher level of D-glucose $(50 \mathrm{mM})$ had significantly affected acrosomal integrity $(P<0.05$, Fig. 3B). Furthermore, the presence of a metabolizable substrate was essential for the maintenance of acrosomal integrity following 2 days of incubation, as was evidenced by the results obtained with L-glucose $(P<0.01$, Fig. 3B).

\section{Spermatozoa mitochondrial function}

Mitochondria play a central role in sperm function (Marchetti et al. 2002, Gallon et al. 2006, Sousa et al. 2011). Moreover, mitochondrial impairment is also an important event in DM (Sivitz \& Yorek 2010). We therefore monitored two aspects of mitochondrial function: superoxide production and MMP.

No differences were observed in the mitochondrial superoxide generation of samples incubated in the different conditions $(P>0.05$, Fig. 4A). However, a significant increase in superoxide production was observed on both days 1 and 2 in L-glucose-incubated spermatozoa $(P<0.05$, Fig. $4 \mathrm{~A})$.

Similarly, no significant glucose-induced effects on MMP were found during any time of incubation $(P>0.05)$, yet substrate availability was shown to be important for mitochondrial activity, as was proven by the decrease in MMP in spermatozoa that were incubated in L-glucose media for 2 days $(P<0.05$, Fig. 4B).

\section{Discussion}

\section{Effects of glucose on spermatozoa functionality}

Although it is somewhat contradictory, the literature suggests that DM might alter sperm function and semen quality, even though the mechanisms involved are poorly understood. In fact, current knowledge has mostly relied on the assessment of conventional sperm parameters that have been shown to be of limited predictive value in the determination of fertility status

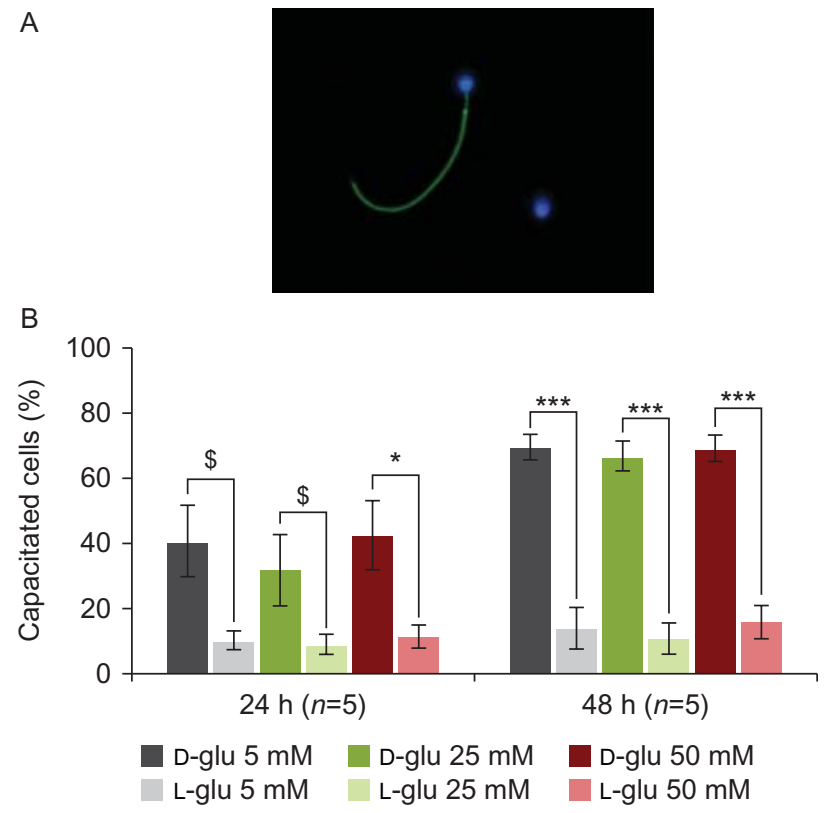

Figure 2 Influence of the different glucose concentrations on protein tyrosine phosphorylation. (A) Immunocytochemical identification of a capacitated spermatozoon on the left (green fluorescence) and a noncapacitated cell on the right (magnification 1000×). (B) Percentage of capacitated spermatozoa. Samples were incubated for 2 days in PBSbased medium with D-glucose (D-glu), whereas osmotic controls were incubated with L-glucose (L-glu), as described in the Materials and methods section. Results are presented as means \pm S.E.M. and the number of experiments is specified. ${ }^{*} P<0.05, * * * P<0.001$. ${ }^{\$}$ Represents statistical trends. 
A

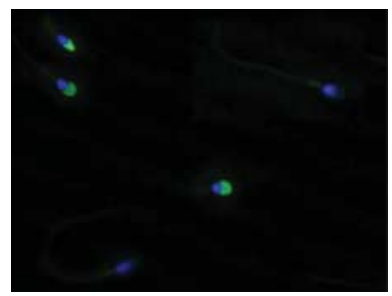

B

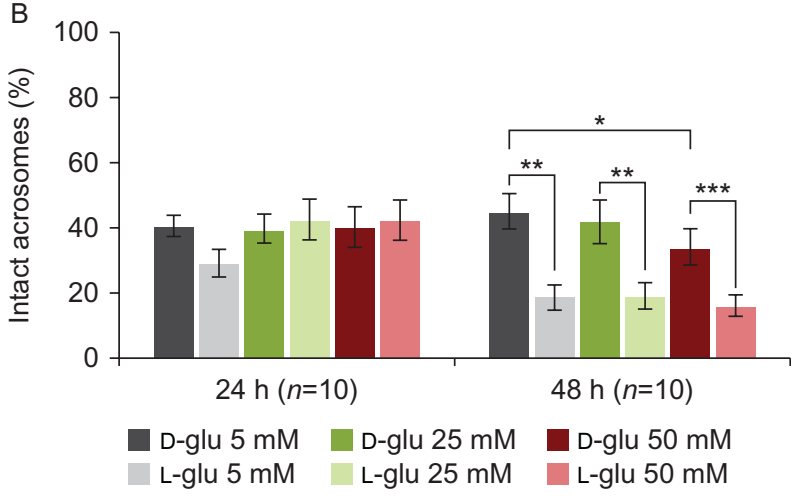

Figure 3 Influence of different glucose concentrations on acrosomal integrity. (A) Spermatozoa with intact acrosomes exhibit homogeneous green fluorescence on the anterior region of the head, whereas acrosome-reacted sperm show only blue nuclear counterstain (magnification $1000 \times$ ). (B) Percentage of spermatozoa with intact acrosomes. Samples were incubated for 2 days in PBS-based medium with D-glucose (D-glu), whereas osmotic controls were incubated with L-glucose (L-glu), as described in the Materials and methods section. Results are presented as means \pm S.E.M. and the number of experiments is specified. ${ }^{*} P<0.05,{ }^{* *} P<0.01,{ }^{* * *} P<0.001$.

(Jequier 2005), which stresses the importance of evaluating more accurate functional sperm parameters that are often ignored in both in vivo and in vitro studies.

Given the extension and multifactorial nature of diabetes-induced physiological changes, there are many mechanisms that might be responsible for the associated reproductive dysfunction. Therefore, the present study strictly addressed the isolated and direct effect of high glucose levels in human spermatozoa during a 2-day incubation period by means of an in vitro experimental system in which male gametes were kept for extended periods of time in a PBS-based medium supplemented with a variety of frequently renewed substances that closely mimic in vivo conditions (Tavares et al. 2013, 2015, Sousa et al. 2014).

Although basic sperm parameters, such as motility and viability, were unaffected by high glucose levels, subtle aspects of sperm function/status were further analyzed.

To become functionally competent, spermatozoa must undergo capacitation within the female tract (Ecroyd et al. 2003) and even though glucose has been reported to be beneficial for human sperm capacitation (Mahadevan et al. 1997, Williams \& Ford 2001), the present results suggest that high glucose levels do not interfere with this process. To our knowledge the present report is the first to address the effects of high glucose levels on capacitation.

On the other hand, $50 \mathrm{mM}$ D-glucose significantly reduced acrosomal integrity on day 2 , and this effect was not justified by alterations in sperm viability, that together with the lack of noticeable changes in capacitation, suggests that the acrosome is more prone to alterations that can possibly interfere with the fertilization process. However, this glucose concentration is not physiologically relevant; it served only as a putative positive control in the present study.

Considering the impact of mitochondrial impairment on both diabetes (Ceriello 2003) and reproductive function (Ramalho-Santos et al. 2009, Amaral et al. 2013b, Ramalho-Santos \& Amaral 2013), we further investigated the possible effect of glucose on sperm mitochondria, particularly on membrane potential, which is essential to the oxidative phosphorylation process, and on ROS production (Ramalho-Santos et al. 2007). To our knowledge, the present study is the first to address such effect on human sperm mitochondria
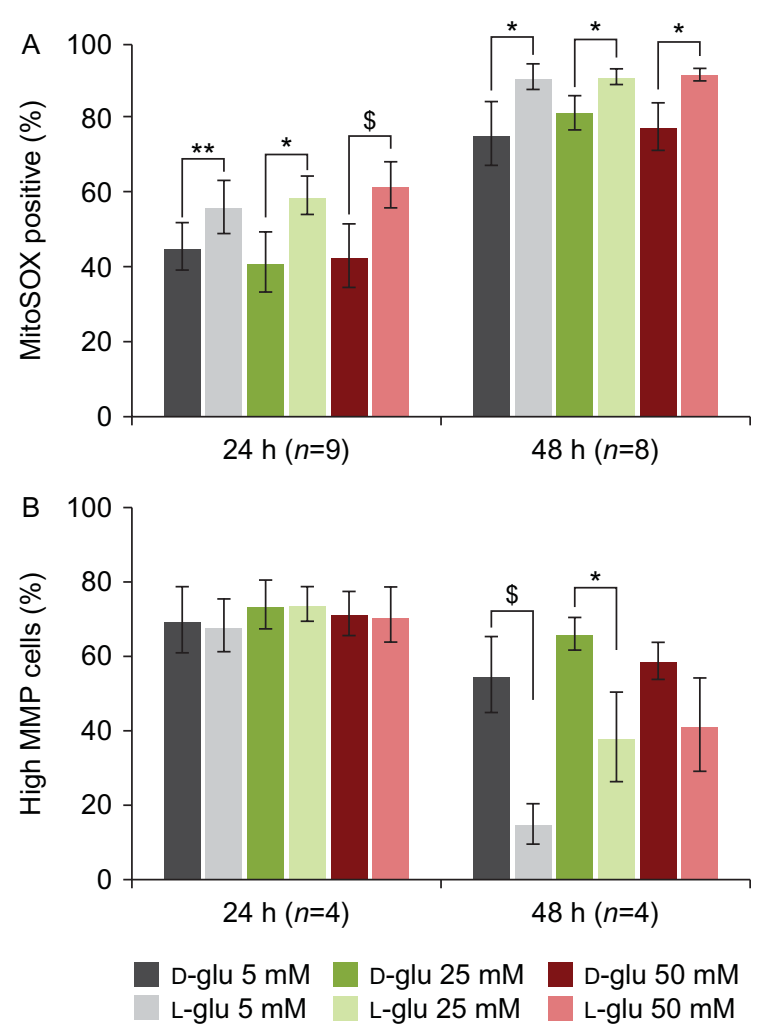

Figure 4 Influence of high glucose levels on sperm mitochondrial superoxide production (A) and mitochondrial membrane potential (MMP) (B). Samples were incubated for 2 days in PBS-based medium with D-glucose (D-glu), whereas osmotic controls were incubated with L-glucose (L-glu), as described in the Materials and methods section. Results indicate the percentage of MitoSOX-Red-positive cells and the percentage of cells with high MMP, respectively. Data is presented as means \pm S.E.M. and the number of experiments is specified. ${ }^{*} P<0.05$, ** $P<0.01$. ${ }^{\$}$ Represents statistical trends. 
functionality. However, the absence of changes at this level might suggest that the alterations previously reported in literature on diabetic sperm function are mitochondria-independent, which is in accordance with reports on rat testicular mitochondria (Amaral et al. 2009).

In summary, the effect of DM on human sperm that has been reported in other in vivo studies may arise from alterations at the spermatogenesis level and/or from factors other than glucose or, alternatively, from a combined effect of glucose and other factors. In fact, it is known that there are many biochemical alterations (e.g., altered insulin levels, increased inflammatory factors, and oxidative status) in diabetic patients, and if those alterations are reflected at the testicular level, along the reproductive tract, or in seminal plasma, their influence on sperm function could be cause for concern.

\section{Effects of substrate availability on spermatozoa functionality}

During all of the experiments osmotic controls were performed using a non-metabolizable glucose (L-glucose). Interestingly, this condition also allowed us to mimic what happens in a diabetic environment, where glucose is present at high levels but is not efficiently used by the cells (Muoio \& Newgard 2008).

L-glucose-incubated spermatozoa presented a significantly lower motility and viability than spermatozoa incubated with a metabolizable glucose (D-glucose). Motility was affected on day 1 but did not interfere with cell viability, so we hypothesized that this effect is a result of a lack of substrate and not of cell death-related processes, although the same cannot be assumed for day 2 . The present results indicate that spermatozoa require glucose to support optimal motility, even when media is supplied with lactate and pyruvate that support mitochondrial respiration. In fact, mammalian sperm require metabolic energy for a variety of functions (Williams \& Ford 2001, Ferramosca \& Zara 2014), and it is known that human spermatozoa obtain a significant proportion of their energy from glycolysis (Williams \& Ford 2001). Nevertheless, the origin of ATP for sperm motility is still being intensely discussed (Ford \& Harrison 1981, Williams \& Ford 2001, Ruiz-Pesini et al. 2007, Bucci et al. 2011, Piomboni et al. 2012).

Additionally, the present results showed that glucose availability is also important for sperm capacitation and acrosomal integrity; this was particularly noticeable on the second day of incubation. In accordance, a number of studies have already demonstrated that the capacitation of human spermatozoa substantially relies on glucose, which suggests a key role for glucose in sustaining hyperactivation (Williams \& Ford 2001), in tyrosine phosphorylation (Travis et al. 2001), and in ensuring IVF (Rogers \& Perreault 1990, Mahadevan et al. 1997). However, it is still unclear whether the beneficial effects of glucose derive from the provision of extra metabolic energy through glycolysis or from the generation of other metabolic products (Aitken et al. 1997, De Lamirande et al. 1997, Williams \& Ford 2001). The higher acrosomal loss observed in L-glucoseincubated spermatozoa may be explained by an early triggered acrosome reaction, possibly because of a continuous lack of metabolizable glucose.

Moreover, in L-glucose-containing media, spermatozoa produced higher amounts of mitochondrial superoxide that may contribute to the decline of several aspects of sperm function (Koppers et al. 2008, Tremellen 2008, Amaral et al. 2013a). Interestingly, we observed that the increased production of ROS occurred before any alteration in MMP became apparent, an effect that has been previously described in human spermatozoa (Koppers et al. 2008, Aitken et al. 2012, Amaral et al. 2013a, Sousa et al. 2014). This points to a deleterious effect of mitochondrial superoxide on mitochondrial functionality which creates a panorama of general mitochondrial dysfunction (Amaral et al. 2013a).

The lower functionality of L-glucose-incubated spermatozoa might be explained by mitochondrial impairment which might also be related to the observed significant decrease in capacitation. In accordance, several studies have demonstrated that concomitant with capacitation, there is an abrupt increase in mitochondrial activity both in mice (Boell 1985, Fraser \& Lane 1987) and human sperm (Hicks et al. 1972, Stendardi et al. 2011). Therefore, if mitochondrial functionality is altered, it can be expected that capacitation might be affected to some extent, as was observed in the present study. However, we cannot exclude that other factors might also be involved.

Overall, glucose availability is essential for the longterm in vitro maintenance of spermatozoa function. Additionally, the present results lead us to suggest that the adverse effects of DM at the sperm level could be explained by a cellular glucose hypometabolism, resultant from the dysfunctional action of insulin in diabetic conditions. Under these conditions, cells have an impaired accessibility to glucose which may lead to cell injury and further reproductive impairment, as has already been reported in the diabetic brain (Liu et al. 2009, Roberts et al. 2014).

\section{Declaration of interest}

The authors declare that there is no conflict of interest that could be perceived as prejudicing the impartiality of the research reported.

\section{Funding}

This study was supported by the Portuguese National Funding Agency for Science and Technology (Fundação para a Ciência e Tecnologia (FCT); grant number EXPL/BEX-BCM/ 
0224/2012). S Amaral was the recipient of an FCT fellowship (number SFRH/BPD/63190/2009), and CNC was funded by FEDER (QREN) through the Programa Mais Centro (grant numbers CENTRO-07-ST24-FEDER-002002, CENTRO-07ST24-FEDER-002006, and CENTRO-07-ST24-FEDER-002008), through the Programa Operacional Factores de Competitividade - COMPETE, and by national funds via the FCT (grant number Pest-C/SAU/LA0001/2013-2014).

\section{Acknowledgements}

The authors especially thank Prof. Teresa Almeida-Santos and Ana Paula Sousa from the Human Reproduction Service of the University Hospitals of Coimbra for their support in sperm collection as well as all of the group members and Ana Duarte for many fruitful discussions. The authors are also grateful to J Saints for the language correction, Isabel Nunes for the help with analyzing the cytometry data, and C Santos for the statistical review.

\section{References}

Agbaje IM, Rogers DA, McVicar CM, McClure N, Atkinson AB, Mallidis C \& Lewis SE 2007 Insulin dependant diabetes mellitus: implications for male reproductive function. Human Reproduction 22 1871-1877. (doi:10.1093/humrep/dem077)

Aitken RJ, Fisher HM, Fulton N, Gomez E, Knox W, Lewis B \& Irvine S 1997 Reactive oxygen species generation by human spermatozoa is induced by exogenous NADPH and inhibited by the flavoprotein inhibitors diphenylene iodonium and quinacrine. Molecular Reproduction and Development 47 468-482. (doi:10.1002/(SICl)1098-2795(199708) 47:4<468::AID-MRD14>3.0.CO;2-S)

Aitken RJ, Gibb Z, Mitchell L, Lambourne SR, Connaughton HS \& De Iuliis GN 2012 Sperm motility is lost in vitro as a consequence of mitochondrial free radical production and the generation of electrophilic aldehydes but can be significantly rescued by the presence of nucleophilic thiols. Biology of Reproduction 87 1-11. (doi:10.1095/ biolreprod.112.102020)

Alves MG \& Oliveira PF 2013 Diabetes Mellitus and male reproductive function: where we stand? International Journal of Diabetology \& Vascular Disease Research 1 101-103.

Amaral A \& Ramalho-Santos J 2010 Assessment of mitochondrial potential: implications for the correct monitoring of human sperm function. International Journal of Andrology 33 e180-e186. (doi:10.1111/j.13652605.2009.00987.x)

Amaral S, Moreno AJ, Santos MS, Seiça R \& Ramalho-Santos J 2006 Effects of hyperglycemia on sperm and testicular cells of Goto-Kakizaki and streptozotocin-treated rat models for diabetes. Theriogenology $\mathbf{6 6}$ 2056-2067. (doi:10.1016/j.theriogenology.2006.06.006)

Amaral S, Mota P, Lacerda B, Alves M, Pereira Mde L, Oliveira PI \& Ramalho-Santos J 2009 Testicular mitochondrial alterations in untreated streptozotocin-induced diabetic rats. Mitochondrion 9 41-50. (doi:10. 1016/j.mito.2008.11.005)

Amaral A, Paiva C, Baptista M, Sousa AP \& Ramalho-Santos J 2011 Exogenous glucose improves long-standing human sperm motility, viability, and mitochondrial function. Fertility and Sterility 96 848-850. (doi:10.1016/j.fertnstert.2011.07.1091)

Amaral S, Redmann K, Sanchez V, Mallidis C, Ramalho-Santos J \& Schlatt S 2013a UVB irradiation as a tool to assess ROS-induced damage in human spermatozoa. Andrology 1 707-714. (doi:10.1111/j.2047-2927. 2013.00098.x)

Amaral A, Lourenço B, Marques M \& Ramalho-Santos J 2013b Mitochondria functionality and sperm quality. Reproduction $\mathbf{1 4 6}$ R163-R174. (doi:10.1530/REP-13-0178)

American Diabetes Association (ADA) 2013 Diagnosis and classification of diabetes mellitus. Diabetes Care 36 S67-574. (doi:10.2337/dc13-S067)
Barták V, Josífko M \& Horácková M 1975 Juvenile diabetes and human sperm quality. International Journal of Fertility 20 30-32.

Boell EJ 1985 Oxygen consumption of mouse sperm and its relationship to capacitation. Journal of Experimental Zoology 234 105-116. (doi:10.1002/jez.1402340113)

Bucci D, Rodriguez-Gil JE, Vallorani C, Spinaci M, Galeati G \& Tamanini C 2011 GLUTs and mammalian sperm metabolism. Journal of Andrology 32 348-355. (doi:10.2164/jandrol.110.011197)

Ceriello A 2003 New insights on oxidative stress and diabetic complications may lead to a "casual" antioxidant therapy. Diabetes Care $\mathbf{2 6}$ 1589-1596. (doi:10.2337/diacare.26.5.1589)

De Lamirande E, Leclerc P \& Gagnon C 1997 Capacitation as a regulatory event that primes spermatozoa for the acrosome reaction and fertilization. Molecular Human Reproduction 3 175-194. (doi:10.1093/molehr/3.3.175)

Delfino M, Imbrogno N, Elia J, Capogreco F \& Mazzilli F 2007 Prevalence of diabetes mellitus in male partners of infertile couples. Minerva Urologica e Nefrologica 59 131-135.

Ecroyd HW, Jones RC \& Aitken RJ 2003 Endogenous redox activity in mouse spermatozoa and its role in regulating the tyrosine phosphorylation events associated with sperm capacitation. Biology of Reproduction 69 347-354. (doi:10.1095/biolreprod.102.012716)

Ferramosca A \& Zara V 2014 Bioenergetics of mammalian sperm capacitationn. BioMed Research International 2014902953. (doi:10.1155/2014/902953)

Ford WC \& Harrison A 1981 The role of oxidative phosphorylation in the generation of ATP in human spermatozoa. Journal of Reproduction and Fertility 63 271-278. (doi:10.1530/jrf.0.0630271)

Fraser LR \& Lane MR 1987 Capacitation- and fertilization related alterations in mouse sperm oxygen consumption. Journal of Reproduction and Fertility 81 385-393. (doi:10.1530/jrf.0.0810385)

Gallon F, Marchetti C, Jouy N \& Marchetti P 2006 The functionality of mitochondria differentiates human spermatozoa with high and low fertilizing capability. Fertility and Sterility 86 1526-1530. (doi:10.1016/j. fertnstert.2006.03.055)

Handelsman DJ, Conway AJ, Boylan LM, Yue DK \& Turtle JR 1985 Testicular function and glycemic control in diabetic men. A controlled study. Andrologia 17 488-496. (doi:10.1111/j.1439-0272.1985.tb01047.x)

Hicks MM, Martínez-Manautou J, Pedron N \& Rosado A 1972 Metabolic changes in human spermatozoa related to capacitation. Fertility and Sterility 23 172-179.

Jequier AM 2005 Is quality assurance in semen analysis still really necessary? A clinician's viewpoint Human Reproduction 20 2039-2042. (doi:10.1093/humrep/dei028)

Koppers AJ, De Juliis GN, Finnie JM, McLaughlin EA \& Aitken RJ 2008 Significance of mitochondrial reactive oxygen species in the generation of oxidative stress in spermatozoa. Journal of Clinical Endocrinology and Metabolism 93 3199-3207. (doi:10.1210/jc.2007-2616)

La Vignera S, Condorelli R, Vicari E, D'Agata R \& Calogero AE 2012 Diabetes mellitus and sperm parameters. Journal of Andrology 33 145-153. (doi:10.2164/jandrol.111.013193)

Liu Y, Liu F, Grundke-Iqbal I, Iqbal K \& Gong CX 2009 Brain glucose transporters, O-GlcNAcylation and phosphorylation of tau in diabetes and Alzheimer's disease. Journal of Neurochemistry 111 242-249. (doi:10.1111/j.1471-4159.2009.06320.x)

Lucas MJ, Leveno KJ, Williams ML, Raskin P \& Whalley PJ 1989 Early pregnancy glycosylated hemoglobin, severity of diabetes, and fetal malformations. American Journal of Obstetrics and Gynecology 161 426-431. (doi:10.1016/0002-9378(89)90536-X)

Mahadevan MM, Miller MM \& Moutos DM 1997 Absence of glucose decreases human fertilization and sperm movement characteristics in vitro. Human Reproduction 12 119-123. (doi:10.1093/humrep/12. 1.119)

Mallidis C, Agbaje I, Rogers D, McCullough S, Atkinson AB, Steger K, Stitt A \& McClure N 2007 Distribution of the receptor for advanced glycation end products in the human reproductive tract: prevalence in men with diabetes mellitus. Human Reproduction 22 2169-2177. (doi:10.1093/humrep/dem156)

Mallidis C, Agbaje IM, Rogers DA, Glenn JV, Pringle R, Atkinson AB, Steger K, Stitt AW \& McClure N 2009 Advanced glycation end products 
accumulate in the reproductive tract of men with diabetes. International Journal of Andrology 32 295-305. (doi:10.1111/j.1365-2605.2007. 00849.x)

Marchetti C, Obert G, Deffosez A, Formstecher P \& Marchetti P 2002 Study of mitochondrial membrane potential, reactive oxygen species, DNA fragmentation and cell viability by flow cytometry in human sperm. Human Reproduction 17 1257-1265. (doi:10.1093/humrep/17.5.1257)

Marchetti P, Ballot C, Jouy N, Thomas P \& Marchetti C 2012 Influence of mitochondrial membrane potential of spermatozoa on in vitro fertilization outcome. Andrologia 44 136-141. (doi:10.1111/j.1439-0272.2010. 01117.x)

Marx J 2002 Unraveling the causes of diabetes. Science 296 686-689. (doi:10.1126/science.296.5568.686)

Miller E, Hare JW, Cloherty JP, Dunn PJ, Gleason RE, Soeldner JS \& Kitzmiller JL 1981 Elevated maternal hemoglobin A1c in early pregnancy and major congenital anomalies in infants of diabetic mothers. New England Journal of Medicine 304 1331-1334. (doi:10.1056/NEJM198105283042204)

Mota PC, Tavares RS, Cordeiro M, Pereira SP, Publicover SJ, Oliveira PJ \& Ramalho-Santos J 2012 Acute effects of TCDD administration: special emphasis on testicular and sperm mitochondrial function. Asian Pacific Journal of Reproduction 1 269-276. (doi:10.1016/S2305-0500(13) 60091-3)

Mulholland J, Mallidis C, Agbaje I \& McClure N 2011 Male diabetes mellitus and assisted reproduction treatment outcome. Reproductive Biomedicine Online 22 215-219. (doi:10.1016/j.rbmo.2010.10.005)

Muoio DM \& Newgard C 2008 Molecular and metabolic mechanisms of insulin resistance and $\beta$ cell failure in type 2 diabetes. Nature Reviews. Molecular Cell Biology 9 193-205. (doi:10.1038/nrm2327)

Nakada K, Sato A, Yoshida K, Morita T, Tanaka H, Inoue S, Yonekawa H \& Hayashi J 2006 Mitochondria-related male infertility. PNAS 103 15148-15153. (doi:10.1073/pnas.0604641103)

Piomboni P, Focarelli R, Stendardi A, Ferramosca A \& Zara V 2012 The role of mitochondria in energy production for human sperm motility. International Journal of Andrology 35 109-124. (doi:10.1111/j.13652605.2011.01218.x)

Publicover SJ, Giojalas LC, Teves ME, de Oliveira GS, Garcia AA, Barratt CL \& Harper CV $2008 \mathrm{Ca}^{2+}$ signalling in the control of motility and guidance in mammalian sperm. Frontiers in Bioscience 13 5623-5637. (doi:10.2741/3105)

Ramalho-Santos J \& Amaral S 2013 Mitochondria and mammalian reproduction. Molecular and Cellular Endocrinology 15 74-84. (doi:10.1016/j.mce.2013.06.005)

Ramalho-Santos J, Amaral A, Sousa AP, Rodrigues AS, Martins L, Baptista M, Mota PC, Tavares R, Amaral S \& Gamboa S 2007 Probing the structure and function of mammalian sperm using optical and Fluorescence microscopy. In Modern Research and Educational Topics in Microscopy, pp 394-402. Eds A Méndez-Vilas \& J Díaz. Extremadura: Formatex.

Ramalho-Santos J, Varum S, Amaral S, Mota PC, Sousa AP \& Amaral A 2009 Mitochondrial functionality in reproduction: from gonads and gametes to embryos and embryonic stem cells. Human Reproduction Update 15 553-572. (doi:10.1093/humupd/dmp016)

Roberts RO, Knopman DS, Cha RH, Mielke MM, Pankratz VS, Boeve BF, Kantarci K, Geda YE, Jack CR Jr, Petersen RC et al. 2014 Diabetes and elevated hemoglobin A1c levels are associated with brain hypometabolism but not amyloid accumulation. Journal of Nuclear Medicine $\mathbf{5 5}$ 759-764. (doi:10.2967/jnumed.113.132647)

Rogers BJ \& Perreault SD 1990 Importance of glycolysable substrates for in vitro capacitation of human spermatozoa. Biology of Reproduction 43 1064-1069. (doi:10.1095/biolreprod43.6.1064)
Ruiz-Pesini E, Diez C, Lapena AC, Pérez-Martos A, Montoya J, Alvarez E, Arenas J \& López-Péres MJ 1998 Correlation of sperm motility with mitochondrial enzymatic activities. Clinical Chemistry 44 1616-1620.

Ruiz-Pesini E, Díez-Sánchez C, López-Pérez MJ \& Enríquez JA 2007 The role of the mitochondrion in sperm function: is there a place for oxidative phosphorylation or is this a purely glycolytic process? Current Topics in Developmental Biology 77 3-19. (doi:10.1016/S0070-2153(6)77001-6)

Sivitz WI \& Yorek MA 2010 Mitochondrial dysfunction in diabetes: from molecular mechanisms to functional significance and therapeutic opportunities. Antioxidants \& Redox Signaling 12 537-577. (doi:10.1089/ars.2009.2531)

Sousa AP, Amaral A, Baptista M, Tavares R, Paiva C \& Ramalho-Santos J 2011 Not all sperm are equal: functional mitochondria characterize a subpopulation of human sperm with better fertilization potential. PLoS ONE 6 e18112. (doi:10.1371/journal.pone.0018112)

Sousa MI, Amaral S, Tavares RS, Paiva C \& Ramalho-Santos J 2014 Concentration-dependent Sildenafil citrate (Viagra) effects in ROS production, energy status, and human sperm function. Systems Biology in Reproductive Medicine 60 72-79. (doi:10.3109/19396368.2013.867380)

Stendardi A, Focarelli R, Piomboni P, Palumberi D, Serafini D, Ferramosca A \& Zara V 2011 Evaluation of mitochondrial respiratory efficiency during in vitro capacitation of human spermatozoa. International Journal of Andrology 34 247-255. (doi:10.1111/j.1365-2605. 2010.01078.x)

Tavares RS, Mansell S, Barratt CL, Wilson SM, Publicover SL \& RamalhoSantos J 2013 p, p'-DDE activates CatSper and compromises human sperm function at environmentally relevant concentrations. Human Reproduction 28 3167-3177. (doi:10.1093/humrep/det372)

Tavares RS, Amaral S, Paiva C, Baptista M \& Ramalho-Santos J 2015 In vitro exposure to the organochlorine $p, p^{\prime}$-DDE affects functional human sperm parameters. Chemosphere 120C 443-446. (doi:10.1016/j.chemosphere.2014.08.075)

Travis AJ, Jorgez CJ, Merdiushev T, Jones BH, Dess DM, Diaz-Cueto L, Storey BT, Kopf GS \& Moss SB 2001 Functional relationships between capacitation-dependent cell signaling and compartmentalized metabolic pathways in murine spermatozoa. Journal of Biological Chemistry 276 7630-7636. (doi:10.1074/jbc.M006217200)

Tremellen K 2008 Oxidative stress and male infertility - a clinical perspective. Human Reproduction Update 14 243-258. (doi:10.1093/ humupd/dmn004)

Vignon F, Le Faou A, Montagnon D, Pradignac A, Cranz C, Winiszewsky P \& Pinget M 1991 Comparative study of semen in diabetic and healthy men. Diabetes \& Metabolism 17 350-354.

Wautier JL \& Schmidt AM 2004 Protein glycation: a firm link to endothelial cell dysfunction. Circulation Research 95 233-238. (doi:10.1161/01. RES.0000137876.28454.64)

Wild S, Roglic G, Green A, Sicree R \& King H 2004 Global prevalence of diabetes: estimates for the year 2000 and projections for 2030. Diabetes Care 27 1047-1053. (doi:10.2337/diacare.27.5.1047)

Williams AC \& Ford WC 2001 The role of glucose in supporting motility and capacitation in human spermatozoa. Journal of Andrology 22 680-695. (doi:10.1002/j.1939-4640.2001.tb02229.x)

World Health Organization (WHO) 2010 In WHO Laboratory Manual for the Examination and Processing of Human Semen, 5th edn. Geneva, Switzerland: WHO Press.

Received 5 March 2015

First decision 1 April 2015

Revised manuscript received 16 April 2015

Accepted 29 April 2015 